\title{
Walking Wednesday: A Program to Promote Physical Activity in Elementary Physical Education
}

\author{
Sheri J. Brock, Danielle D. Wadsworth, Jessica Richards and Brenna Cosgrove \\ School of Kinesiology \\ Auburn University, Auburn, Alabama, USA \\ Leah E. Robinson \\ School of Kinesiology \\ University of Michigan, Ann Arbor, Michigan, USA
}

\begin{abstract}
There is a need to promote daily physical activity in schoolage populations. This preliminary study examined the benefits of a school-based physical activity promotion program, Walking Wednesday, on step counts during Physical Education in elementary students. Step counts were monitored during three consecutive PE classes ( $N=144$, mean age $10.64 \pm .62$ years). Physical Education Walking Wednesday (PE -Walking Wednesday) required students to complete one mile at their own pace on one day per week before participation in Physical Education. On PE-Tuesday and PE-Thursday participants engaged in a traditional Physical Education lesson. Results indicated participants accumulated an average of 1450 more steps on PE-Walking Wednesday compared to PE-Tuesday and PE-Thursday $(p<.001)$. Boys accumulated more steps $(p<.001)$ on PE-Tuesday and PE-Thursday compared to girls. However, no sex differences were present on PEWalking Wednesday $(p=.460)$. The PE-Walking Wednesday program led to more physical activity and eliminated sex differences observed in elementary students' physical activity behavior during PE.
\end{abstract}

Keywords: pedometer; step count; school-age children; physical education intervention.

\section{Introduction}

Obesity rates are at an all-time high with one out of every three children in the United States being overweight or obese (Ogden et al., 2016). Regular participation in physical activity reduces the risk of hypokinetic diseases, such as cardiovascular disease, type II diabetes, and obesity. Engaging in sedentary behaviors, along with poor dietary and health choices, threatens children's quality of life. Therefore, increasing physical activity participation in children is 
a national priority. Current recommendations state that children, aged $5-18$ years, should engage in a minimum of 60 minutes of daily, moderate-tovigorous physical activity (MVPA) that incorporates the cardiorespiratory and musculoskeletal systems (United States Department of Health \& Human Services, 2008). Despite the benefits of regular participation in physical activity, a majority of elementary students are not meeting this recommendation. Nationally, only $42 \%$ of children aged 6-11 years participate in 60 minutes of MVPA per day (Colabianchi et al., 2016; Troiana et al., 2008) and girls engage in significantly less physical activity than boys (Colabianchi et al., 2016; Robinson, Wadsworth, \& Peoples, 2012). Hubbard et al., (2016) reported 15\% of 517 grade 3-5 school children participated in 60 minutes of total daily physical activity, with girls achieving fewer minutes than boys ( 8.0 vs. $25.7 ; p<0.0001$ ). Therefore, from a health promotion perspective, there is a need to promote daily physical activity in school-age children, particularly for girls.

\section{Providing Physical Activity During the School Day}

More than $95 \%$ of children in the United States between the ages of 5 - 17 years are enrolled in schools (Snyder, \& Dillow, 2012). Children spend most of their waking hours in schools which provides schools the ability to promote physical activity and energy expenditure through various opportunities (e.g., recess periods, intramural/interscholastic sports programs, Physical Education/school policies) (van Landeghem, 2003). Unfortunately, MVPA accrued during the school day is reportedly below recommendations. Galloway, Owens and Van Blerk (2015) noted 6.4 minutes of MVPA during recess and 2.6 minutes of MVPA during PE for $4^{\text {th }}$ grade students. Efrat (2013) determined that verbal prompting could increase MVPA during recess by 2.41 minutes in elementary level students, although the increases were below daily recommendations. Similarly, interventions utilizing activity trackers or accelerometers have noted increases in physical activity during recess, however the authors also cited the brevity and informal nature of recess time as a detriment to increasing physical activity during recess to achieve daily recommendations (Hayes \& Van Camp, 2015; Morabia \& Costanza, 2009).

Physical Education (PE) is a formal, school-based curriculum that provides an opportunity for children to be physically active in an allocated amount of time (Sallis, et al., 2003). There are mixed reports as to children's physical activity participation during PE periods (Mckenzie, et al., 1996; Simons-Morton et al., 1994). Robinson et al., (2014) used the System for Observing Fitness Instruction Time (SOFIT) to examine physical activity engagement during PE in 683 elementary students across five schools in rural Alabama. On average, students spent $23.80 \pm 5.33 \mathrm{~min} /$ day in PE and $14.33 \pm 6.10 \mathrm{~min} /$ day were spent in MVPA (Robinson, et al., 2014). In a study of grade 3-6 students, Booker, Galloway and Doering (2018) discovered only 23.83\% of allotted PE time resulted in MVPA. Additionally, studies have shown that trained researchers were successful in increasing MVPA utilizing a mastery motivational climate (Johnson et al., 2017; Logan et al., 2015; Rudisill, 2016; Rudisill \& Johnson, 2018; Wadsworth et al., 2013). 


\section{Curricular Programming to Increase Physical Activity}

Research has shown that physical activity participation can be enhanced during PE through a variety of programs. Sports, Play, and Active Recreation for Kids (SPARK) - is a health-related fitness curricular approach that has been used to promote physical activity in elementary students (Sallis et al., 1997). Sallis, et al., (1997) found that fourth and fifth graders who participated in SPARK-PE spent 18 more minutes in MVPA compared to a traditional PE program. Similar findings were reported from Verstraete et al.'s replication utilizing SPARK-PE with European school-age children (Verstraete et al., 2007). Specifically, European school-age children increased their MVPA by $14 \%$ across the intervention (i.e., $42 \%$ at pretest to $56 \%$ at posttest). Fu et al., (2016) also found increased physical activity levels while utilizing the SPARK-PE program, however differences were not significant for girls in grade 7. Barrett et al., (2015) projected MVPA could be increased by 16\% through SPARK-PE and CATCH (Child and Adolescent Trial for Cardiovascular Health) program implementation. McKenzie et al. (2003) noted a 15\% increase in MVPA using $\mathrm{CATCH}$ with children in elementary school, and MVPA increased or was maintained 5-7 years later. Jago, et al., (2009) found that the incorporation of activity-based programs during PE resulted in 585 grade 6 students spending an average of $52-62 \%$ of the PE period with a mean heart rate greater than the cutpoint thresholds for MVPA (i.e., 140 beats per minute), but again the mean heart rate for girls was significantly lower than for boys. Other studies have reported that physical activity programs were not effective in eliminating sex differences in physical activity (Faucette, et al., 1995; Strong et al., 2005). Regardless of the increased amount of time spent in MVPA, sex differences were still present due to girls participating in significantly less physical activity than boys. Thus, it will be beneficial to continue to explore PE programming approaches that promote physical activity while eliminating sex differences.

Elementary PE programming can provide students with substantially more physical activity that could potentially influence a large population of school-age children. Programs like SPARK-PE and CATCH have been shown to be effective, but are costly and do not promote physical activity among sexes equally. In particular, Barrett et al., (2015) projected the price tag of implementing SPARK-PE and CATCH as a PE policy in 46 states would cost millions of U.S. dollars that would unlikely be appropriated. A need exists to find an innovative, low-cost approach that promotes physical activity in the PE setting that could potentially result in long-lasting health benefits for all children. Additionally, because girls tend to be less active than boys, these programs need to aid in eliminating sex differences related to physical activity. The purpose of this study was to examine the benefits of a school-based physical activity promotion program, PE-Walking Wednesday, on step counts during PE in elementary students. A secondary purpose was to examine sex differences in physical activity as a result of the PE-Walking Wednesday program. 


\section{Methods}

In this section we will describe the students in the study and the setting for which they participated in Physical Education daily. An overview of the validated instruments and procedures used in the study will be provided, followed by a description of the traditional Physical Education lessons and the PE-Walking Wednesday condition. Finally, the methods used for data analysis will be outlined.

\section{Participants}

Parental consent was obtained from $1694^{\text {th }}$ and $5^{\text {th }}$ grade students $(88$ girls and 81 boys; $\mathrm{M}$ age $=10.43 \pm .62$ years) from a nationally recognized Blue Ribbon School for academic excellence located in a suburban middle class community in the southeastern United States. Students' race/ethnic background was classified as White (64.6\%), African American (25.7\%), Hispanic (5.3\%), and not specified (4.4\%). The school's PE facilities included two large outdoor spaces with a playground area and one indoor space (i.e., cafeteria, available only during inclement weather). The school was well equipped with PE equipment, and had one certified PE teacher (male instructor) and one PE assistant (female instructor). Class sizes ranged from 40-45 students, and children received 30-min of daily PE.

\section{Instruments}

Physical activity was measured with the Omron HJ-720ITC Pedometer (Omron Healthcare, Inc; Bannockburn, IL) across three consecutive days (Tuesday, Wednesday, and Thursday). The Omron HJ-720ITC pedometer is a small battery-operated device, $17 / 8^{\prime \prime}(\mathrm{w}) \quad 27 / 8^{\prime \prime}(\mathrm{h}) \times 5 / 8^{\prime \prime}(\mathrm{d})$ that weighs approximately 1.25 ounces, and features dual piezoelectric sensors, allowing steps to be accumulated in a vertical and horizontal plane. The pedometer has been tested for validity in prescribed and self-paced conditions and demonstrates an absolute percent error of $<3.0 \%$ (Holbrook, Barreira \& Kang, 2009). This percent error indicates that fewer than 3 missed steps occur per every 100 steps. This criterion has been accepted for pedometer validity (Crouter et al., 2003). The Omron pedometer offers PC downloading capabilities and includes a 7-day recall on the pedometer display and a 41-day storable memory for measures of daily step counts. Other advantages of this device are that it records step accumulation by time, resets automatically at midnight, and cannot be reset manually. The pedometer was secured to its holder, clipped to each participant's waist band, and for added security each pedometer was then secured with a strap that clipped to the waist band or belt loop. Steps accumulated within PE served as the dependent variable for this study.

\section{Procedures}

Before the start of the study, permission was granted by the school PE teachers and administrators to collect data regarding the effectiveness of the PE-Walking Wednesday program. The study was approved by the Institutional Review 
Board, and parental/guardian consent was obtained. Each child was assigned a pedometer calibrated according to their stride length, height, and weight as specified in the pedometer manual. Stride length was calculated by the distance participants walked in 10 strides divided by 10. Participants received oral instructions regarding the monitors, and devices were placed on each participant upon arrival to PE on Tuesday, Wednesday, and Thursday. The participants were familiar with pedometers from previous activities that incorporated the devices in their class.

\section{Physical Education Lessons}

Children participated in a traditional PE lesson on Tuesday and Thursday. The PE program focused on providing developmentally appropriate activities to foster fundamental motor skill development, physical activity, and contribute to lifelong health and fitness. Students were commonly involved in large and small group activities that incorporated student fitness, basic motor skills (i.e., locomotor and manipulative skills), and physical activity. On Tuesday and Thursday during data collection the students participated in a teacher-directed chasing, fleeing and dodging games lesson that did not have a competitive focus or include elimination.

\section{Physical Education - Walking Wednesday Condition}

The PE-Walking Wednesday was a physical activity promotion program integrated into the school's PE program. On Wednesday, the PE period began with students walking or jogging four laps around the outdoor field that equated to 1 mile. For the remainder of the Wednesday lesson, children had the autonomy to choose their own PE activity based on the lessons taught on Tuesday/Thursday. The purpose of this within-subject study was to examine the effectiveness of this PE-Walking Wednesday physical activity promotion program on students' physical activity during PE. Therefore, all participants received both conditions as part of their regularly scheduled PE program.

\section{Data Analysis}

The dependent variable in all analyses were step counts which represent the accumulated number of steps during the 30-min PE periods on Tuesday, Wednesday, and Thursday. Descriptive statistics were generated to describe the mean step count for participants during each 30-min PE period. To examine the effect of the school-based physical activity promotion program, PE-Walking Wednesday, on step counts during $\mathrm{PE}$, three paired sample $t$-tests were conducted that examined mean differences between PE-Tuesday and PEWalking Wednesday, PE-Walking Wednesday and PE-Thursday, and PETuesday and PE-Thursday. All significance levels for the $t$-tests were adjusted to $p=0.016(0.05 / 3)$ using the Bonferroni correction factor. To examine sex differences a 2 (Sex) X 3 (Day) ANOVA was conducted and significance was set at $p=.05$. Data were analyzed using IBM SPSS Statistics version 23 . 


\section{Results}

Participants with data for all three consecutive daily PE classes (Tuesday, Wednesday, and Thursday) were used in the final data analysis which resulted in a sample of 144 participants (74 girls and 70 boys). Descriptive results for PE steps are presented in Figure 1. Overall, participants accumulated an average of: 1346.85 steps \pm 712.20 (PE-Tuesday), $2823.06 \pm 1001.31$ (PE-Walking Wednesday), and 1394.84 steps \pm 848.61 (PE-Thursday) during the 30-minute PE period. Paired sample $t$-tests revealed significant differences between PETuesday and PE-Walking Wednesday $(t(143)=-22.64, p<.001)$ and PE-Walking Wednesday and PE-Thursday $(t(143)=19.507, p<.001)$. On average, participants accumulated an average of 1,450 more steps on PE-Walking Wednesday. No significant differences were present between PE-Tuesday and PE-Thursday ( $p=$ $.341)$.

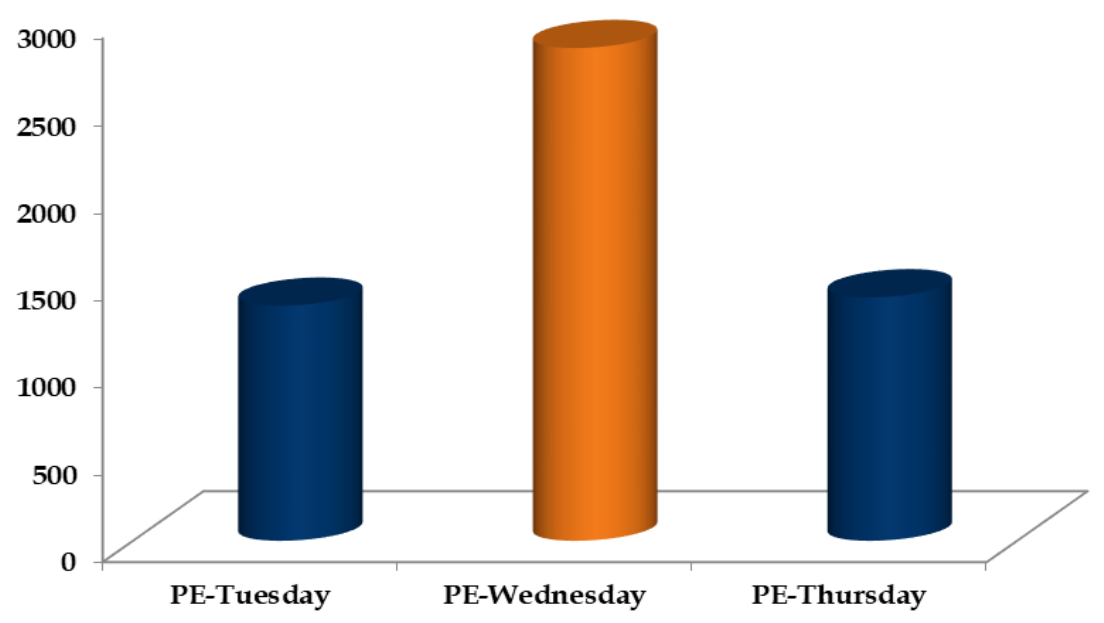

Figure 1. Step count accumulation across three PE days.

In terms of sex differences, boys accumulated significantly more steps on PETuesday $[F(1,142)=10.78, p<.001]$ and PE-Thursday $[F(1,142)=8.981, p<.001$, Figure 2]. Boys achieved 1540.74 steps \pm 801.85 on PE-Tuesday and 1606.91 steps \pm 1015.16 on PE-Thursday which is on average 390 more steps than girls (1163.44 steps \pm 561.89, PE-Tuesday; 1194.24 steps \pm 593.88, PE-Thursday. No sex differences were present in total step count accumulated on PE-Walking Wednesday $(p=.460)$. 


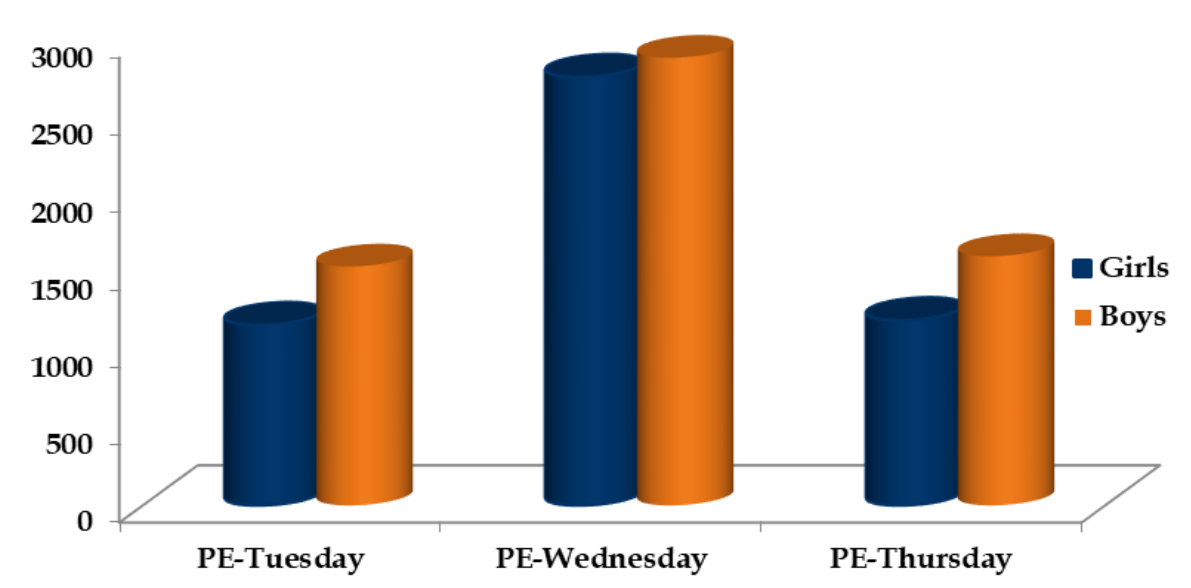

Figure 2. Step count accumulation across three PE days by sex.

\section{Discussion}

Since children spend a majority of their day at school (van Landeghem, 2003), the school environment can contribute to children meeting physical activity recommendations, particularly during PE. The purpose of this study was to determine the effect of a PE-Walking Wednesday school-based physical activity program during PE on elementary students' physical activity. Results support this simple program significantly enhanced school-age children's step count during PE. This program also eliminated sex differences between girls and boys. The PE-Walking Wednesday program enabled girls to accumulate step counts comparable to boys during PE.

Public health scientists have developed and tested various approaches to increase physical activity levels in elementary-age children. It is essential for interventions to be both widely used and cost-effective to have a lasting influence from a public health standpoint. Large-scale curriculum-based PE interventions such as SPARK and CATCH have shown to be effective in providing quality PE instruction and improving physical activity and enjoyment during class time (Barrett et al., 2015; Faucette, et al., 1995; Fu et al., 2016; Jago et al., 2005; Jago, et al., 2009). Both SPARK and CATCH require teacher training, school resources, and a costly curriculum that may not be available for all schools. The PE-Walking Wednesday program evaluated in this paper is simple and cost-effective. The PE- Walking Wednesday program resulted in increased physical activity during PE and could be implemented in any elementary school that has an area to walk. This simple walking program could be applied to multiple settings and provide physical activity opportunities outside of PE (i.e., during recess and lunch periods).

In reference to physical activity, boys accumulate between 42 - 49\% and girls 41 $47 \%$ of their daily steps during the school day (Tudor-Locke et al., 2009). Specific studies that examined pedometer step count during PE show that boys can accumulate 1,200 - 2,300 and girls can accumulate 1,300 - 1,800 steps in a 50minute PE class. This step count represents 8.7 to $23.7 \%$ for boys and 11.4 to 
$17.2 \%$ for girls of their daily in-school step count (Tudor-Locke, et al., 2009). Based on the literature, boys tend to accumulate more physical activity than girls, and that trend appears to be consistent during PE. The National Health and Nutrition Examination Survey data support that sex is a major contributing factor to disparities in physical activity (Whitt-Glover, et al., 2009).

Differences in physical activity during PE based on sex might be attributed to girls having lower self-efficacy (Dishman, et al., 2004), activities that are not perceived as culturally- and gender-relevant (Azzarito \& Solmon, 2005; Caballero, et al., 2003), activities that are not enjoyable (Dishman, et al., 2004; Robinson et al., 2012; Young, et al., 2006), and a lack of peer support (NeumarkSztainer et al., 2003). Definitive conclusions cannot be speculated for this study since psychosocial and environmental barriers within the PE program were not assessed. The PE-Walking Wednesday program did result in more physical activity among preadolescent girls and warrants the need for further investigation.

One possible explanation for the success of this program is that it did not emphasize competition or encourage peer outcome comparisons of steps accumulated, lap times, or 1-mile times. The National Association for Sport and Physical Education (SHAPE, 2014) has clearly outlined standards for the physically educated person with the major goal of developing individuals that maintain a healthful level of physical activity for a lifetime. Unfortunately, competitive activities are often a part of PE programs which discourage some students from engagement and may cause children to lose intrinsic motivation to participate in PE (Hastie, Rudisill \& Wadsworth, 2013; Robinson, 2011; Robinson et al., 2010; Singleton, 2003; Wadsworth \& Robinson, 2010). This could be especially true for students who possess low skill ability and girls. Van Daalen (2005) explored why girls' participation in PE is dwindling and revealed that many PE programs were the source of shaming regarding athletic ability due to forced competition, degrading, and perceived gender inappropriate activities (Van Daalen, 2005). The PE-Walking Wednesday program examined in this study was rooted in student participation, as opposed to being based on competition or athletic ability. Students were not told to complete the laps at a specific pace or time, but rather they were instructed to complete four full laps around the field at their own pace. The students may have also been motivated to engage in more physical activity on Wednesday because they were given the opportunity to choose their own activities after they completed their 1-mile walk. Evidence suggests that young children engage in more physical activity when they have autonomy in the level of engagement (Hastie et al., 2013; Rudisill, 2016; Rudisill \& Johnson, 2018; Singleton, 2003; Wadsworth \& Robinson, 2010).

\section{Limitations}

This study is not without limitations. The Walking Wednesday Program was evaluated in one elementary school, and results are not generalizable to larger samples. Participants' data only represents a snapshot of the Walking 
Wednesday program. Data were collected for three consecutive days; PETuesday, PE-Walking Wednesday, and PE-Thursday and did not occur over multiple weeks nor was the order of conditions counter-balanced. Inferences cannot be made regarding the long-term effects of the PE-Walking Wednesday program, but nonetheless would be interesting to explore.

Future projects should assess the long-term effects of a year-long program on both physical activity during PE, as well as other opportunities during and after the school day. We are unable to distinguish between the total amount of steps that were accumulated during the different components of the PE - Walking Wednesday program (i.e., steps to complete the 1-mile versus the remaining PE lesson). Findings from this study can only be generalized to preadolescent children. Replication with youth, ages $13-18$, would provide insight as it relates to the effectiveness of this type of PE approach in secondary PE settings. Future studies should consider various psychosocial and environmental barriers that may influence physical activity participation and the long-term effects of a school-based walking program on physical activity. Since walking is the most common form of physical activity for adults (Kohl III \& Cook, 2013), the effect of walking programs for elementary schools should be evaluated longitudinally. It would also be beneficial to examine the effectiveness of a walking program using a control group that could compare the direct effect of the program on physical activity behavior. The walking program was established within the school PE program, and the goal was to test the effectiveness of the walking program before more large-scale and controlled studies.

\section{Conclusions}

Schools are in a unique position to aid in obesity prevention strategies. In 2013, the National Academies of Sciences, Engineering, and Medicine released "Educating the Student Body: Taking Physical Activity and Physical Education to School"(Kohl III \& Cook, 2013). One recommendation from this report was to make physical activity an integral and routine component of both the PE and school environment (Kohl III \& Cook, 2013). Schools are an ideal setting for physical activity programs, effective PE programming, along with educational and lifestyle interventions that promote behavior change. Findings from this preliminary study support the PE-Walking Wednesday program led to more physical activity for $4^{\text {th }}$ and $5^{\text {th }}$ graders during PE. The physical activity program was effective in eliminating sex differences between boys' and girls' physical activity levels during the entire PE session. The PE-Walking Wednesday program was a simple, low resource, and cost effective program that increased physical activity in pre-adolescent children and enabled girls to accumulate comparable steps to boys during PE. Additionally, the program did not require teacher training and in fact Walking Wednesday was created by the teachers at the school and embedded in the PE curriculum on a weekly basis prior to this study. In this initial study we determined that Walking Wednesday achieved the goal of increasing physical activity and eliminating sex differences. Future qualitative methods of analysis could be robustly informative to describe the 
perspectives of students and teachers, and potentially provide substantial evidence to explore such programs longitudinally and with various age groups.

\section{References}

Azzarito, L., \& Solmon, M. A. (2005). A reconceptualization of physical education: The intersection of gender/race/social class. Sport, Education and Society, 10(1), 25-47. https://doi.org/10.1080/135733205200028794

Barrett, J. L., Gortmaker, S. L., Long, M. W., Ward, Z. J., Resch, S. C., Moodie, M. L., ... \& Cradock, A. L. (2015). Cost effectiveness of an elementary school active physical education policy. American Journal of Preventive Medicine, 49(1), 148-159. https://doi.org/10.1016/j.amepre.2015.02.005

Booker, R., Galloway, R., \& Doering, T. (2018). Evaluation of in-school physical activity during recess, pe, and academically-related movement activities: 1248 Board\# 56 May 31 9. Medicine and Science in Sports and Exercise, 50(5S), 290-291. https://doi.org/10.1249/01.mss.0000536042.34975.be

Caballero, B., Clay, T., Davis, S. M., Ethelbah, B., Rock, B. H., Lohman, T., ... \& Stevens, J. (2003). Pathways: A school-based, randomized controlled trial for the revention of obesity in American Indian schoolchildren. The American Journal of Clinical Nutrition, 78(5), 1030-1038. https://doi.org/10.1093/ajcn/78.5.1030

Colabianchi, N., Griffin, J. L., McIver, K. L., Dowda, M., \& Pate, R. R. (2016). Where are children active and does it matter for physical activity? A latent transition analysis. Journal of Physical Activity and Health, 13(12), 1294-1300. https://doi.org/10.1123/ipah.2015-0607

Crouter, S. E., Schneider, P. L., Karabulut, M., \& Bassett, D. R. (2003). Validity of 10 electronic pedometers for measuring steps, distance, and energy cost. Medicine and Science in Sports and Exercise, 35(8), 1455-1460. https://doi.org/10.1249/01.mss.0000078932.61440.a2

Dishman, R. K., Motl, R. W., Saunders, R., Felton, G., Ward, D. S., Dowda, M., \& Pate, R. R. (2004). Self-efficacy partially mediates the effect of a school-based physicalactivity intervention among adolescent girls. Preventive Medicine, 38(5), 628-636. https://doi.org/10.1016/j.ypmed.2003.12.007

Efrat, M. W. (2013). Exploring effective strategies for increasing the amount of moderate- to- vigorous physical activity children accumulate during recess: A quasi- experimental intervention study. Journal of School Health, 83(4), 265-272. https://doi.org/10.1111/josh.12026

Faucette, N., Sallis, J. F., McKenzie, T., Alcaraz, J., Kolody, B., \& Nugent, P. (1995). Comparison of fourth grade students' out-of-school physical activity levels and choices by gender: Project SPARK. Journal of Health Education, 26(sup2), S82-S90. https://doi.org/10.1080/10556699.1995.10603153

Fu, Y., Gao, Z., Hannon, J. C., Burns, R. D., \& Brusseau Jr, T. A. (2016). Effect of the SPARK program on physical activity, cardiorespiratory endurance, and motivation in middle-school students. Journal of Physical Activity and Health, 13(5), 534-542. https://doi.org/10.1123/jpah.2015-0351

Galloway, J. R., Owens, S. G., \& van Blerk, N. (2015). Characterizing PE, recess, and academically-related movement activities relative to moderate-to-vigorous physical activity. Medicine $\mathcal{E}$ Science in Sports \& Exercise, 47(5S), 243. https://doi.org/10.1249/01.mss.0000477091.73359.49

Hastie, P. A., Rudisill, M. E., \& Wadsworth, D. D. (2013). Providing students with voice and choice: lessons from intervention research on autonomy-supportive climates in physical education. Sport, Education and Society, 18(1), 38-56. https://doi.org/10.1080/13573322.2012.701203 
Hayes, L. B., \& Van Camp, C. M. (2015). Increasing physical activity of children during school recess. Journal of Applied Behavior Analysis, 48(3), 690-695. https://doi.org/10.1002/jaba.222

Holbrook, E. A., Barreira, T. V., \& Kang, M. (2009). Validity and reliability of Omron pedometers for prescribed and self-paced walking. Medicine and Science in Sports and Exercise, 41(3), 670-674. https://doi.org/10.1249/mss.0b013e3181886095

Hubbard, K., Economos, C. D., Bakun, P., Boulos, R., Chui, K., Mueller, M. P., \& Sacheck, J. (2016). Disparities in moderate-to-vigorous physical activity among girls and overweight and obese schoolchildren during school-and out-of-school time. International Journal of Behavioral Nutrition and Physical Activity, 13(1), 39. https://doi.org/10.1186/s12966-016-0358-x

Jago, R., Baranowski, T., Baranowski, J. C., Thompson, D., \& Greaves, K. A. (2005). BMI from 3-6 y of age is predicted by TV viewing and physical activity, not diet. International Journal of Obesity, 29(6), 557. https://doi.org/10.1038/sj.ijo.0802969

Jago, R., McMurray, R. G., Bassin, S., Pyle, L., Bruecker, S., Jakicic, J. M., ... \& Volpe, S. L. (2009). Modifying middle school physical education: piloting strategies to increase physical activity. Pediatric Exercise Science, 21(2), 171-185. https://doi.org/10.1123/pes.21.2.171

Johnson, J. L., Rudisill, M. E., Sassi, J., Wadsworth, D., \& Hastie, P. (2017). Instructional matters: Influence of instruction on motor skill learning across different mastery motivational climate conditions. European Journal of Physical Education and Sport Science, 3(9), 24-34. http://dx.doi.org/10.5281/zenodo.1066398

Kohl III, H. W., \& Cook, H. D. (Eds.). (2013). Educating the student body: Taking physical activity and physical education to school. National Academies Press. https://doi.org/10.17226/18314

Logan, S. W., Robinson, L. E., Webster, E. K., \& Rudisill, M. E. (2015). The influence of instructional climates on time spent in management tasks and physical activity of 2nd-grade students during physical education. European Physical Education Review, 21(2), 195-205. https://doi.org/10.1177/1356336x14555304

McKenzie, T. L., Li, D., Derby, C. A., Webber, L. S., Luepker, R. V., \& Cribb, P. (2003). Maintenance of effects of the $\mathrm{CATCH}$ physical education program: Results from the CATCH-ON study. Health Education and Behavior, 30(4), 447-462. https://doi.org/10.1177/1090198103253535

McKenzie, T. L., Nader, P. R., Strikmiller, P. K., Yang, M., Stone, E. J., Perry, C. L., ... \&.Kelder, S. H. (1996). School physical education: effect of the child and adolescent trial for cardiovascular health. Preventive Medicine, 25(4), 423-431. https://doi.org/10.1006/pmed.1996.0074

Morabia, A., \& Costanza, M. C. (2009). Active encouragement of physical activity during school recess. Preventive Medicine, 4(48), 305-306. https://doi.org/10.1016/j.ypmed.2009.03.014

Neumark-Sztainer, D., Story, M., Hannan, P. J., Tharp, T., \& Rex, J. (2003). Factors associated with changes in physical activity: a cohort study of inactive adolescent girls. Archives of Pediatrics and Adolescent Medicine, 157(8), 803-810. https://doi.org/10.1001/archpedi.157.8.803

Ogden, C. L., Carroll, M. D., Lawman, H. G., Fryar, C. D., Kruszon-Moran, D., Kit, B. K., \& Flegal, K. M. (2016). Trends in obesity prevalence among children and adolescents in the United States, 1988-1994 through 2013-2014. JAMA, 315(21), 2292-2299. https://doi.org/10.1001/jama.2016.6361

Robinson, L. E. (2011). Effect of a mastery climate motor program on object control skills and perceived physical competence in preschoolers. Research Quarterly for 
Exercise

and

Sport, 82(2),

$355-359$

https://doi.org/10.5641/027013611x13119541884301

Robinson, L.E., Reynolds J., Wadsworth, D. D., \& Logan, S.W. (2010). The effects of physical play instructional climates on physical activity in preschool-age children. Science and Sports, 25(3), 4-13.

Robinson, L. E., Wadsworth, D. D., \& Peoples, C. M. (2012). Correlates of school-day physical activity participation in preschoolers: A preliminary study. Research Quarterly for Exercise and Sport, 83(1), 20-26. https://doi.org/10.1080/02701367.2012.10599821

Robinson, L. E., Wadsworth, D. D., Webster, E. K., \& Bassett Jr, D. R. (2014). School reform: The role of physical education policy in physical activity of elementary school children in Alabama's black belt region. American Journal of Health Promotion, 28(sp3), S72-S76. https://doi.org/10.4278/ajhp.130430-arb-207

Rudisill, M. E. (2016). Mastery motivational climates: motivating children to move and learn in physical education contexts. Kinesiology Review, 5(3), 157-169. https://doi.org/10.1123/kr.2016-0009

Rudisill, M. E., \& Johnson, J. L. (2018). Mastery motivational climates in early childhood physical education: What have we learned over the years?. Journal of Physical Education, Recreation \& Dance, 89(6), 26-32. https://doi.org/10.1080/07303084.2018.1476940

Sallis, J. F., McKenzie, T. L., Alcaraz, J. E., Kolody, B., Faucette, N., \& Hovell, M. F. (1997). The effects of a 2-year physical education program (SPARK) on physical activity and fitness in elementary school students. Sports, Play and Active Recreation for Kids. American Journal of Public Health, 87(8), 1328-1334. https://doi.org/10.2105/ajph.87.8.1328

Sallis, J. F., McKenzie, T. L., Conway, T. L., Elder, J. P., Prochaska, J. J., Brown, M., ... \& Alcaraz, J. E. (2003). Environmental interventions for eating and physical activity: a randomized controlled trial in middle schools. American Journal of Preventive Medicine, 24(3), 209-217. https://doi.org/10.1016/s0749$\underline{3797(02) 00646-3}$

Simons-Morton, B. G., Taylor, W. C., Snider, S. A., Huang, I. W., \& Fulton, J. E. (1994). Observed levels of elementary and middle school children' s physical activity during physical education classes. Preventive Medicine, 23(4), 437-441. https://doi.org/10.1006/pmed.1994.1059

Singleton, E. (2003). Rules? Relationships?: A feminist analysis of competition and fair play in physical education. Quest, 55(2), 193-209. https://doi.org/10.1080/00336297.2003.10491799

Snyder, T. D., \& Dillow, S. A. (2012). Digest of Education Statistics, 2011. NCES 2012-001. National Center for Education Statistics.

Society of Health and Physical Educators. (2014). National standards \& grade-level outcomes for K-12 physical education.

Strong, W. B., Malina, R. M., Blimkie, C. J., Daniels, S. R., Dishman, R. K., Gutin, B., ... \& Rowland, T. (2005). Evidence based physical activity for school-age youth. The Journal of Pediatrics, 146(6), 732-737. https:// doi.org/10.1016/i.jpeds.2005.01.055

Troiano, R. P., Berrigan, D., Dodd, K. W., Masse, L. C., Tilert, T., \& McDowell, M. (2008). Physical activity in the United States measured by accelerometer. Medicine and Science in Sports and Exercise, 40(1), 181-188. https://doi.org/10.1249/mss.0b013e31815a51b3

Tudor-Locke, C., McClain, J. J., Hart, T. L., Sisson, S. B., \& Washington, T. L. (2009). Expected values for pedometer-determined physical activity in youth. Research 
$\begin{array}{llll}\text { Quarterly for Exercise and Sport, 80(2), 164-174. } & \text {. }\end{array}$ https://doi.org/10.5641/027013609x13087704028075

United States Department of Health, \& Human Services. (2008). 2008 physical activity guidelines for Americans: Be active, healthy, and happy! (Vol. 36). US Government Printing Office. https://doi.org/10.1037/e525412010-001

Van Daalen, C. (2005). Girls' experiences in physical education: Competition, evaluation, \& degradation. The Journal of School Nursing, 21(2), 115-121. https://doi.org/10.1622/1059-8405(2005)021[0115:geipec]2.0.co;2

VanLandeghem, K. (2003). Preventing obesity in youth through school-based efforts. Issue Brief. NGA Center for Best practices. 1-10.

Verstraete, S. J., Cardon, G. M., De Clercq, D. L., \& De Bourdeaudhuij, I. M. (2007). Effectiveness of a two-year health-related physical education intervention in elementary schools. Journal of Teaching in Physical Education, 26(1), 20-34. https://doi.org/10.1123/itpe.26.1.20

Wadsworth, D. D., \& Robinson, L. E. (2010). The relationship among pedometer step count, perceived physical competence, sex and body mass index to actual motor competence in preschool-age children. 1st World Congress for Physical Activity and Health in Young Children. Vol 25. Epinal, France: Science and Sports; 19-25.

Wadsworth, D. D., Robinson, L. E., Rudisill, M. E., \& Gell, N. (2013). The effect of physical education climates on elementary students' physical activity behaviors. Journal of School Health, 83(5), 306-313. https://doi.org/10.1111/josh.12032

Whitt-Glover, M. C., Taylor, W. C., Floyd, M. F., Yore, M. M., Yancey, A. K., \& Matthews, C. E. (2009). Disparities in physical activity and sedentary behaviors among US children and adolescents: Prevalence, correlates, and intervention implications. Journal of Public Health Policy, 30(1), S309-S334. https://doi.org/10.1057/jphp.2008.46

Young, D. R., Johnson, C. C., Steckler, A., Gittelsohn, J., Saunders, R. P., Saksvig, B. I., ... \& McKenzie, T. L. (2006). Data to action: Using formative research to develop intervention programs to increase physical activity in adolescent girls. Health Education and Behavior, 33(1), 97-111. https://doi.org/10.1177/1090198105282444 